\title{
Nuevas perspectivas sobre la religiosidad popular o religión común de los andaluces
}

\author{
New perspectives on the popular religiosity or common religion of Andalusians
}

\author{
Salvador Rodríguez Becerra \\ Catedrático de Antropología Social. Universidad de Sevilla. \\ becerra@us.es
}

\author{
30 ANIVERSARIO DE LA GAZETA DE ANTROPOLOGÍA \\ NÚMERO COORDINADO POR FRANCISCO CHECA OLMOS Y CELESTE JIMÉNEZ DE MADARIAGA
}

\begin{abstract}
RESUMEN
El artículo precisa los contenidos de la que llamo 'religión común' tratando de superar las imprecisiones de la llamada 'religiosidad popular', concepto connotado por la Iglesia Católica que la considera como desviación de la norma y que constituye la religión real objeto de estudio de las ciencias sociales.
\end{abstract}

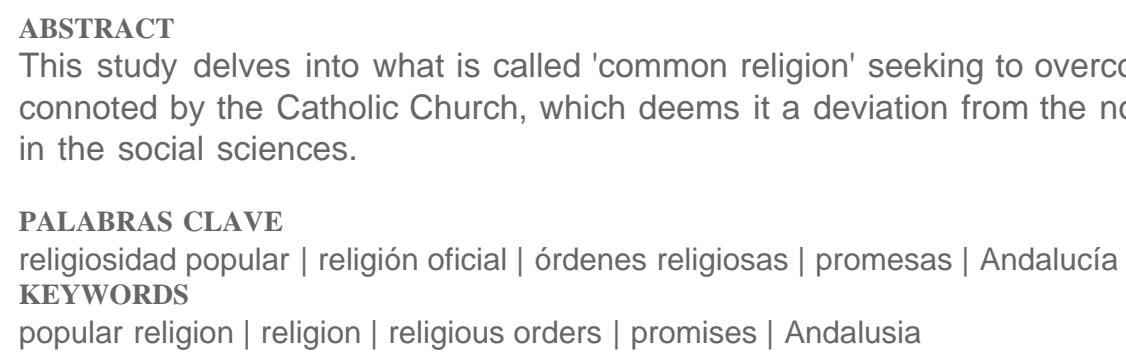
in the social sciences.

PALABRAS CLAVE

religiosidad popular | religión oficial | órdenes religiosas | promesas | Andalucía KEYWORDS

popular religion | religion | religious orders | promises | Andalusia

This study delves into what is called 'common religion' seeking to overcome the inaccuracies of the concept of 'popular religion' connoted by the Catholic Church, which deems it a deviation from the norm and holds that it is the real object of religious study

\section{Introducción}

Inevitablemente esta exposición tendrá que ser sintética y de carácter general, aunque Andalucía estará latente en todo el texto; aquí sólo podré apuntar mi actual concepción sobre la llamada religiosidad popular, que prefiero llamar religión común (1). La Iglesia Católica es la más unificada de todas las existentes, como lo atestiguan su grado de centralismo, jerarquización, estrecho control de la doctrina, unidad de los rituales y universalización de sus símbolos. Esta unidad no ha sido, sin embargo, nunca una realidad total, pues ha sido adaptada e incluso rota en multitud de ocasiones por sociedades o grupos de tradición cristiana; incluso dentro de la misma institución existen grupos que parten de concepciones y actitudes diferenciadas de la postura oficial, tales como órdenes, congregaciones e institutos religiosos y grupos autónomos que se sienten parte de ella, pero que no siguen todos sus postulados, sin olvidar las peculiaridades de las iglesias nacionales y misioneras. Esta unidad se resiente aun más si tenemos en cuenta la diversidad cultural, propia de cada una de las sociedades y países en los que el catolicismo está presente, amén de otras particularidades propias de clases sociales, género y formas de subsistencia. La historia y la antropología han aportado la evidencia de la imposibilidad de exportar a otros pueblos cualquier religión en su integridad, por ser éstas producto de unas circunstancias históricas y tradiciones culturales.

Los sistemas religiosos conforman y son conformados por los sistemas culturales y mentales, por lo que para comprenderlos es necesario trascender nuestro propio sistema de pensamiento. En último término, una religión no es una mera acumulación de creencias, ritos e instituciones sino un sistema integrado de interpretación del hombre y del mundo. La religión es un componente más de las culturas que incluye a 
los seres sobrenaturales; por ello es inadecuado concebir a las religiones aisladas del contexto sociocultural e histórico que las produce, transforma y conserva. Existe por ejemplo, una relación de causa-efecto entre las devociones a determinadas imágenes y las condiciones medioambientales, socioeconómicas y circunstancias históricas que las favorecieron o perjudicaron.

Toda religión, aunque fuera única en su doctrina, que en la práctica no lo es, se vive de forma diferente por cada sociedad; estas diferencias no son de menor cuantía, aunque se diga lo contrario, sino que afectan incluso a la concepción doctrinal básica. Las diferencias en las formas de vivir la religión no solo afectan a los rituales, forma exteriorizada y fundamental en las sociedades, sino también a los contenidos doctrinales; estas diferencias se ignoran o simplemente se despachan por las iglesias motejándolas de "supersticiosas" y/o heréticas. Esto se explica porqué el común de las gentes, antes y ahora, reinterpreta los mensajes doctrinales que recibe pasándolos por el filtro de su propia cultura, adaptándolos e incluso rechazándolos, aunque con frecuencia con resistencia pasiva más que con enfrentamientos directos.

Tampoco puede obviarse el poder de la Iglesia a partir de Teodosio (2) y la influencia de sus disposiciones normativas y los liderazgos en la conformación de la religiosidad, pero es de todos conocido, que las meras disposiciones legales no crean cultura por si solas. La Antropología Social no niega el componente sobrenatural o espiritual en la cultura, como se critica con frecuencia, pero afirma que éste está condicionado por las estructuras y circunstancias sociohistóricas de cada pueblo; es asimismo engañoso creer que el mantenimiento de las formas religiosas implica también el de los contenidos y sus significados.

Llamo la atención sobre la confusión bastante generalizada entre los conceptos de iglesia y religión que para muchos en nuestro país son equivalentes. Las iglesias son instituciones que interpretan, adaptan y mantienen la doctrina con una estructura de poder, mientras que la religión es el conjunto de creencias, rituales e instituciones que dan sentido sobrenatural a la existencia humana. Buena prueba de la diferencia es el hecho que muchas religiones carecen de iglesia institucionalizada. Otra pareja de conceptos que conviene distinguir son los de norma y vida, que no son siempre coincidentes e incluso contradictorios; las normas morales guían la vida cuando se corresponden con los sistemas de valores propios o están avaladas por la coacción, pero en cuanto ésta cesa, generalmente se vuelve a situaciones anteriores o similares. Solo cuando se dan las condiciones infraestructurales necesarias, la sociedad hace suya ciertas normas, pero en todo caso siempre las transforma. El poder y la coacción que le es inherente puede hacer creer que sus normas se incorporan al patrimonio inmaterial de la sociedad, pero su debilitamiento supone el fin de las mismas. Siempre hay diferencias -cuando no verdaderos abismos- entre el ideal postulado y la realidad vivida. Diferenciar estos conceptos me parece fundamental para entender el desarrollo de lo que expondremos a continuación.

Una última idea antes de terminar esta introducción. Las órdenes religiosas o clero regular, especialmente las mendicantes, a las que considero versiones propias y organizativas del cristianismo, son en gran parte las conformadoras de las formas y símbolos de la llamada religiosidad popular andaluza. Éstas durante el Antiguo Régimen, especialmente en Andalucía, donde se habían implantado extensamente, vivieron una dura competencia en la que cada orden ofrecía una espiritualidad propia y un programa iconográfico y teológico diferenciado y unos privilegios espirituales para atraer a los creyentes a su ámbito -podríamos hablar de fidelización-, lo que les permitía establecerse, crecer y si era posible, superar a las otras, dentro del paraguas de poder institucional, ideológico y ritualista que ofrecía la Iglesia católica. El clero secular dotado de ciertos medios de subsistencia, y por ello más alejado del pueblo y de poder coactivo, ejercerá una tarea más rutinaria que creativa e influirá menos en la conformación de la religiosidad de los andaluces (3).

La metodología de este trabajo y en general la de todos mis escritos, parten de la observación del presente y simultáneamente de la búsqueda de apoyaturas en los textos del pasado, tan profusos y ricos entre nosotros, porque la religión del presente es en parte producto del pasado, pero no mera continuidad. La religión cambia, incluso en los principios que se consideran permanentes, pero evoluciona a un ritmo diferente de la tecnología y la sociedad, y la cultura en su conjunto. La idea del infierno y el purgatorio, la indisolubilidad del matrimonio o el celibato sacerdotal están puestas hoy en 
cuestión o superadas por la mayoría de los cristianos. Esta metodología nos permite comprender mejor y más eficazmente el presente con la ayuda del pasado.

\section{La religiosidad popular: un concepto controvertido}

En los últimos decenios las ciencias sociales han utilizado el concepto de religiosidad popular frente al de religión, a falta de otro más preciso, aunque también se ha usado por algunos, no sin fundamento, el de religión popular; recientemente y tras muchos debates, se comienza a desestimar su uso por impreciso, cuando no por interesado. Religiosidad refiere fundamentalmente a la praxis mientras que el de religión pone el énfasis en las creencias y dogmas; dicho de otra manera, el término religiosidad sería más contingente, e incluye el sentido de desviación de la norma, mientras que el de religión, tiende a lo permanente, lo que desde el discurso eclesiástico viene a significar verdad frente a error, conceptos muy cuestionados por la Antropología social. En cuanto al concepto de popular, también muy controvertido, refiere al común del pueblo, es decir, ajeno a la tradición de las elites, y aunque sabemos que ambas tradiciones se han mantenido históricamente separadas, se han influenciado mutuamente como ha ocurrido sobre todo en las artes. Pero bajo el concepto de pueblo no siempre se han incluido los mismos sectores sociales ni los mismos contenidos semánticos. Así, los exvotos o los milagros, por ejemplo, se consideran una manifestación de religiosidad popular y sin embargo, unos y otros eran creencias y prácticas seguidas hasta muy recientemente por eclesiásticos y personas cercanas a la oligarquía religiosa y civil.

La llamada religiosidad popular se desenvuelve entre el racionalismo que reduce el discurso y las actitudes humanas a un logos sin sentimientos ni imágenes, y el romanticismo que establece que lo único válido es lo peculiar. La mayoría de los estudiosos está de acuerdo en la existencia de un contraste entre lo popular y lo oficial, en que la religión popular está siempre situada históricamente, y en que la auténtica religión popular es la incesante búsqueda de la trascendencia que se encuentra en la convivencia humana asentada en la tradición y movida por razones históricas y actuales.

La llamada religiosidad popular, caracterizada por algunos por su anacronismo y dependencia, nacida del retraso económico y el tardío acceso de los jóvenes a la enseñanza superior, con lo que ello conlleva de ausencia de educación en los valores racionales y científicos, se expresa por sus manifestaciones barrocas. Probablemente este apego por lo barroco se corresponde con los períodos de mayor esplendor de esta forma de religión en Andalucía, los siglos XVI-XVIII. La estética barroca, reelaborada por la concepción romántica que exalta la sensualidad, se ha convertido en un canon riguroso del que salirse es casi imposible. Ésta, además de contar con el criterio inapelable de los expertos y artistas ha calado hondo en el sentido popular, de forma que otras sensibilidades artísticas no encuentran lugar en las manifestaciones religiosas. Pero lo barroco no se expresa solo en la estética sino también en la forma de entender y vivir la religión; así, para las cofradías lo religioso es entendido sobre todo como culto externo y en el procesionar de las imágenes, actividades a las que subordinan casi toda su capacidad económica y de organización, y sus sentimientos religiosos. Para los cofrades, no poder sacar las imágenes titulares por las calles de su pueblo o ciudad en la Semana Mayor supone un fracaso.

La llamada religiosidad popular está penetrada, orientada e informada por la doctrina y las instituciones eclesiásticas que han sido en el pasado una forma de poder que controlaba comportamientos y conciencias, dado que éstas disponían de plena capacidad coactiva. Estas circunstancias históricas han provocado, entre otros, el rechazo de ciertas normas y principios, la aceptación de otros y la reinterpretación de la mayoría. En los últimos decenios, como consecuencia en gran parte del régimen de libertades establecidas en la Constitución, se detecta un fuerte incremento de las manifestaciones de religiosidad pública apoyadas sobre todo en hermandades, junto a una creciente secularización apoyada en la ciencia y la tecnología, aunque persisten las creencias mágicas. Existen también grupos minoritarios renovadores que viven su propia versión de la fe cristiana bien diferenciada de la oficial, unos de carácter progresista, ajenos a la jerarquía aunque dentro de la institución, y otros, representativos de movimientos sociales conservadores, muy apegados al papado. Simultáneamente, se 
observa una escasa influencia de las instituciones eclesiásticas en la vida de los españoles. Buena prueba de ello es la amplia aceptación entre cristianos del divorcio, la contracepción, la sexualidad prematrimonial, junto a la escasa asistencia a misa, la renuencia al pago de impuestos para el mantenimiento de la institución y otras respuestas nacidas de la libre decisión, lo que prueba que el factor religioso no determina el comportamiento de la mayoría de los ciudadanos.

En último término, pero no por ello menos importante, hay que situar el problema de la transmisión y aceptación de ideas y creencias, es decir, la posibilidad de difundir o exportar modelos, lo que se conoce como evangelización, catequización o recristianización. Partimos del principio de que el receptor de los mensajes no recibe con la misma valoración todo lo que le envía el emisor; es más, ciertos mensajes no entran en la lógica de ciertas culturas, grupos o individuos, o, simplemente, la problemática que se les plantea no existe para el interlocutor. Los mecanismos de transmisión no se pueden plantear en términos de buena o mala enseñanza, pues el mensaje emitido, aun suponiendo que sea homogéneo, está destinado a unos receptores diversos y frecuentemente ajenos al emisor, por lo que el resultado será una nueva construcción mental y unas acciones o rituales semejantes, pero no iguales. Esta construcción se forja a partir de la tradición y de las peculiares circunstancias y formas de entender el mundo, la sociedad y su entorno en el devenir histórico. Los mensajes serán reelaborados y adaptados, es decir, pasados por el filtro de la propia cultura, lo que puede denominarse percepción religiosa común.

En la actualidad, la religión común de la mayoría de los ciudadanos es concebida y vivida de forma distinta, incluso en aspectos fundamentales; éstos seleccionan del conjunto de creencias y directrices eclesiales aquéllas que consideran razonables, concordantes con su cultura y valores y ajustadas al tiempo presente, lo que algunos Ilaman "religión a la carta", sin que por ello dejen de considerarse cristianos y miembros de la iglesia. La fiesta se considera la mejor ocasión para establecer el diálogo del hombre necesitado con lo sobrenatural, expresado fundamentalmente a través de promesas y exvotos. Estas expresiones no invalidan otras formas de experiencia religiosa ordinaria, de carácter privado, tales como la oración y la recepción de sacramentos. Éstos, a título de ejemplo no son valorados de la misma forma ni tienen el mismo significado por el común de la ciudadanía, dándose incluso, en alguno de ellos, una inversión del sentido 0 , simplemente, se les excluye de la práctica ordinaria, como ocurre con la penitencia y la extremaunción.

\section{De la religiosidad popular a la religión común de los andaluces}

La llamada religiosidad popular desde la perspectiva oficial es considerada imperfecta cuando no desviada, que aunque tiene algo de positivo, siempre -dicen- habrá que limpiarla de adherencias erráticas, tradiciones, creencias y ceremonias superfluas y contaminadas. $Y$ es que la institución eclesiástica soporta a duras penas la religión no eclesiástica, pues como dice el jesuita y filósofo de la religión Gómez Caffarena: "La autoridad eclesiástica..., no está sin más con la religiosidad popular, la cultiva como indispensable clientela" (1993). En los últimos decenios se percibe una valoración positiva por parte de la jerarquía, aunque siempre con recelo, porque no la controla en todos sus aspectos, así para el obispo Asenjo de Córdoba, hoy arzobispo de Sevilla, la religiosidad popular es sobre todo un freno a la secularización (Sierra Albarrana 2007).

Y es que la institución eclesiástica se mueve en el ámbito de un modelo ideal, en el debe ser, frente a la religión practicada y vivida por la mayoría que es un modelo real, del ser, encarnado en una cultura. Ambos modelos no son estáticos y aunque se insiste continuamente en la inmutabilidad del modelo ideal, el hecho es que ha sido redefinido continuamente por concilios, sínodos y pastorales, incluso en los conceptos y misterios fundamentales. Trento ha sido el referente durante siglos. Por otra parte, ambos modelos se mueven en una dinámica de mutuas influencias, aunque no puede olvidarse que el modelo oficial ha sido el dominante hasta el siglo XIX y es lógico pensar que haya dejado huellas muy marcadas.

La distinción entre estos dos modelos solo es válida a efectos analíticos porque no es real, es decir, no existe en ningún lugar o tiempo, porque una religión no puede considerarse como tal hasta tanto una 
sociedad no le da vida, la encarna y la pone en práctica, y, desde ese mismo momento se vuelve contingente. Toda interpretación del núcleo de doctrina y la acción de ella derivada es por naturaleza diversa y adaptada a las circunstancias de cada sociedad. En este sentido pues, es preferible llamar a las creencias y rituales, así como a las formas institucionales en las que se desenvuelven los ciudadanos de cada comunidad, religión común de los... andaluces, españoles o cubanos (4). Esta propuesta conceptual es de la misma naturaleza que lo son las de cultura, literatura o arte propios de una región o comarca concretas, lo que quiere decir que son culturas, literaturas o economías singulares que participan de otras más amplias como la española, europea o americana, con las que se interrelacionan, pero que se estructuran y manifiestan con rasgos suficientemente significativos y peculiares que la diferencian de otras.

El clero y los agentes pastorales están divididos respecto a la postura a tomar ante la llamada religiosidad popular, fomentándola unos y combatiéndola otros; los obispos en general, mantienen desde el último tercio del siglo pasado y comienzos del actual, una postura de apoyo entusiasta a estas formas de religión, purificándola de elementos espurios; por el contrario, muchos curas jóvenes en el mismo período, querían acabar con la religiosidad popular pues veían en ella todos los males de la sociedad y la religiosidad tradicionales: injusticia, egoísmo, gasto superfluo y conservadurismo, junto a formalismo, ritualidad vacua y folclorismo. Valgan como muestra lo expresado por el dominico J. Duque: “... hay que tener en cuenta las tremendas dificultades pastorales que se presentan desde el momento y hora que se desee revitalizar evangélica y pastoralmente las asociaciones y manifestaciones de Religiosidad Popular...; los esfuerzos que se han gastado, los hombres y mujeres que se han desfondado en la tarea... y los resultados apenas se han visto" (Duque 1986). Las generaciones recientes de curas, que como sabemos son muy reducidas, siguen a la jerarquía eclesiástica.

La postura de apoyo de la jerarquía, como responsable de la continuidad de la institución eclesiástica, no fue condescendiente en décadas anteriores con esta forma de religiosidad; quizás ahora, fundamenta su postura en el deseo de que la iglesia siga siendo la institución fuerte y poderosa de tiempos pasados, apoyada en la multitud de creyentes que siguen esta expresión religiosa; pero quizás, lo que ocurre es que la institución eclesiástica confunde creyentes con fieles, y en el sur peninsular hay muchos de los primeros pero pocos de los segundos. Por otra parte, es importante señalar que el modelo ideal propugnado por la clerecía tampoco es homogéneo y en su definición pugnan visiones distintas del cristianismo.

\section{Caracterización de la religión común}

La religión común presupone la existencia de seres sobrenaturales a los que se les dirigen rituales que son considerados centrales en la relación con el hombre. También contempla la existencia de fuerzas sobrenaturales que se expresan a través de seres humanos o de forma independiente. El ritual supone prácticas privadas y públicas y se expresa a través de comportamientos con cierta autonomía, es decir, no controlados en todos sus términos por las iglesias; solo se acepta a los clérigos como legitimadores de ciertos actos en los que su presencia se considera necesaria. Está así mismo dirigida a satisfacer las necesidades primarias: salud, trabajo, protección contra las catástrofes y fertilidad; tiene un sentido pragmático pues busca el beneficio y la respuesta a las necesidades más perentorias; para obtener estos fines ofrece compensaciones a los seres sobrenaturales y hace ofrendas propiciatorias como inversión de futuro.

La religión común puede detectarse en todas las grandes religiones y de ella participan la mayoría de los miembros de la sociedad, incluso los no creyentes, por cuanto la religión y la lengua constituyen los rasgos culturales que mejor identifican a los grupos. Esto no es solo característico de la población rural o campesina sino también de la urbana. Por ello, puede decirse que es interclasista y localista. La religión común puede caracterizarse como emotiva, circunstancial, festiva y externa en sus manifestaciones. En síntesis, la religión común es una forma de religión en la que "las relaciones con lo divino son más sencillas, más directas y más rentables", según estableciera Meslin. 
Supone una praxis poco intelectualista, con predominio del sentimiento y de la imaginación; es sobre todo una religión vivida y participativa, sin excluir las actitudes individuales. Muestra poco interés o incomprensión por los misterios elaborados por los teólogos considerados verdades dogmáticas, así las del Dios trinitario, la concepción inmaculada de María, la encarnación de Dios en mujer o el pecado original como herencia de los supuestos primeros padres. Igualmente, a la permanente sumisión a la divinidad preconizada por la Iglesia opone el do ut des, es decir, te doy para que me des, tan claramente expresado en la promesa y el exvoto. Se da así mismo una gran importancia al milagro. El hombre reconoce sus limitaciones como animal racional y espera de los poderes sobrenaturales la solución de sus problemas que no puede solventar con sus propios recursos. Históricamente se comprueba esto aunque en la actualidad el milagro ocupe un lugar muy marginal en la teología oficial, sin que ello signifique la negación de su existencia histórica (Aguirre 2002). Frente a los cambios en la pastoral eclesiástica se ofrece resistencia; frente a la racionalización de la fe que llevan a cabo los teólogos, el pueblo convive sin excesivas preocupaciones con los misterios y los hechos extraordinarios. La distinción entre magia y religión no es clara, pues frecuentemente aparecen mezcladas y ambas se usan como opciones simultáneas o alternativas en respuesta a las necesidades.

Es selectiva, pues acepta unas creencias y prácticas y margina otras. A modo de ejemplo: los sacramentos son desigualmente aceptados; se reciben los que constituyen ritos de paso como el bautismo y el matrimonio mientras que la confirmación, penitencia, comunión y extremaunción son aceptados ocasionalmente o incluso rechazados. Pueden detectarse creencias y rituales de religiones más antiguas sincretizadas y muy estragados, como en las fiestas de la cruz de mayo. No obstante, "La religiosidad popular no se constituye con los restos de una ignorancia secular del pueblo, sino en el proceso también secular de asentamiento de la religión oficial" (García García 1989, I: 29). Porque la religión común no surge espontáneamente, ni permanece inalterada en el tiempo, sino que es el resultado de la dialéctica entre los especialistas de lo religioso -históricamente detentadores del poder- y la mayoría de la población. Es una realidad cultural connotada socialmente, cuyas modalidades son históricamente variables en relación dialéctica con las modalidades culturales y religiosas hegemónicas y con los sucesos históricos generales (Lombardi Satriani 1989 I: 56).

\section{Conclusión}

Considero que la religión común es la religión de la mayoría de los ciudadanos, y por ello la religión real de un pueblo, sin olvidar que actualmente sectores significativos en el mundo occidental no tienen ninguna religión; todo lo demás es superestructura dominante que en parte la ha conformado, pero que no la ha modificado esencialmente (5).

Así, persiste el modelo de relación diádica de los hombres con los seres y fuerzas sobrenaturales que aunque desigual, no es de absoluta sumisión por parte de los hombres y que se expresa a través de claves culturales propias, una de cuyas manifestaciones más conocidas es la promesa. Por todo ello propongo denominar a las religiones comunes con apelativos de las sociedades y culturas, de ahí el título de mi libro La Religión de los andaluces.

\section{Notas}

1. Las ideas expuestas en este trabajo han sido tratadas con mayor amplitud en mi libro La Religión de los Andaluces. Editorial Sarriá, Málaga, 2006.

2. El Edicto de Tesalónica promulgado por el emperador Teodosio en el año 380, no solo declara al Cristianismo como religión oficial -única y obligatoria- del Imperio, sino que tacha a los renuentes a acatar el edicto de "locos y heréticos" y decreta que "sus lugares de reunión no serán considerados como iglesias y serán destruidos...". 
3. El clero secular de las diócesis andaluces, especialmente los curas y capellanes, durante el Antiguo Régimen, no contó con medios económicos suficientes para mantenerse dignamente, salvo el alto clero de catedrales y colegiatas y algunos de los beneficiados parroquiales; éstos, al menos para el caso del arzobispado de Sevilla y hasta la reforma de los curatos en 1791 gozaron de las mejores rentas.

4. Mi propuesta no es una novedad pues ya fue expuesta en el I Congreso de Religiosidad popular celebrado en Sevilla en 1980 por P. Córdoba y otros, aunque con cierta suspicacia por parte de muchos (Córdoba 1989).

5. Entendida como el conjunto de fenómenos jurídicos-políticos e ideológicos, tales como el derecho, el estado, las religiones, las manifestaciones, y demás; así como las instituciones que las representan en una sociedad determinada.

\section{Bibliografía}

Aguirre, Rafael (ed.)

2002 Los milagros de Jesús. Perspectivas metodológicas plurales. Estella, Verbo Divino.

Álvarez Santaló, Carlos (María Jesús Buxó y Salvador Rodríguez Becerra) (coords.)

1989 Religiosidad popular, 3 vols. Barcelona, Anthropos.

Castón, Pedro (y J. López)

2005 "La Religiosidad en Andalucía. Valores y participación”, en Jaime Andreu Abela (coord.), Desde la esquina de Europa. Análisis comparado del capital social en Andalucía, España y Europa. Sevilla, CEA: 239-272.

Córdoba Montoya, Pedro

1989 "Religiosidad popular: arqueología de una noción polémica", Religiosidad popular, I: 70-81.

Duque, Jesús

1986 "Claves bibliográficas de la Religiosidad Popular Andaluza", Communio, nº XIX: 227-238.

García García, José Luis

1989 "El concepto de religiosidad popular", Religiosidad popular, I: 19-29.

Gómez Caffarena, José (ed.)

1993 Religión. Madrid, Trotta.

Lombardi Satriani, Luigi

1989 "El hombre como derrota de Dios", Religiosidad popular, I: 55-69.

Meslin, Michel

1978 Aproximación a una ciencia de las religiones. Madrid, Cristiandad.

Rodríguez Becerra, Salvador

2006 La Religión de los andaluces. Málaga, Editorial Sarriá.

2008 "Las órdenes mendicantes y la religiosidad en Andalucía", en Manuel Jiménez Pulido (F. Siles y S. Ramírez), La Tercera orden regular en Andalucía. Caños Santos. Historia y vida de un desierto franciscano en los confines del reino de Sevilla. Ronda, Editorial la Serranía: XVII-XXVI.

2008 "Los exvotos como expresión de las relaciones humanas con lo sobrenatural. Nuevas perspectivas 
desde Andalucía", México y España. Un océano de exvotos: gracias concebidas, gracias recibidas. Zamora, Museo Etnográfico de Castilla y León: 95-119.

2008 "Las órdenes religiosas y la religiosidad durante el Barroco", Congreso Internacional Andalucía Barroca: IV. Ciencia, Filosofía y Religiosidad. Actas, Sevilla, Consejería de Cultura. Junta de Andalucía: 171-195 (en colaboración con S. Hernández González).

2009 "Las romerías, entre lo sagrado y lo profano. Una perspectiva antropológica desde Andalucía", en Salvador Rodríguez Becerra, Las romerías. Ritos y símbolos. Salamanca, Diputación de Salamanca: 1129.

2009 "La Semana Santa de Andalucía: algo más que una manifestación religiosa", Bandue. Revista de la Sociedad Española de Ciencias de las Religiones (Madrid), III: 101-214.

2009 "De la religiosidad popular a la religión de los andaluces", en S. Rodríguez Becerra y C. Macías Sánchez (coords.), El fin del campesinado. Sevilla, Centro de Estudios Andaluces: 167-192.

2012 "Advocaciones marianas de gloria en Andalucía. Génesis y evolución de sus santuarios", en Javier Campos (coord.), Advocaciones Marianas de Gloria. San Lorenzo de El Escorial, Estudios Superiores del Escorial: 91-106. 